\title{
PQ analysis of a rooftop solar PV: a grid connected PV system pilot project in Indonesia
}

\author{
Hadi Suhana ${ }^{1,2} \&$ Ngapuli I. Sinisuka ${ }^{2}$ \\ ${ }^{I}$ P.T. PLN (Persero) Kantor Pusat, Indonesia \\ ${ }^{2}$ School of Electrical Engineering and Informatics, \\ Bandung Institute of Technology, Indonesia
}

\begin{abstract}
Electrical power quality (PQ) disturbance has become a prominent issue in Indonesia. On a distribution network, it is mainly caused by a nonlinear load. Due to the varying power produced, it is affected by a solar PV system as well. Therefore it is necessary to take a solar photovoltaic (PV) without battery storage into account on evaluating a PQ problem. This paper presents observation results of a rooftop PQ system interconnected to the distribution network which supplies nonlinear loads. In this paper, electrical PQ measurements and harmonic levels of rooftop solar PV integration are presented. The PQ measurements were set up on a distribution network which supplied a nonlinear load individually and whenever a PV system is interconnected with it. As is known, the level of harmonics depend on the performance of a PV system inverter. Since IEEE 1547-2003 standard applies to the measurement results, it is revealed that a PV system inverter is not meeting the standard. To prevent excessive levels of harmonic current injected by a solar PV system, risk mitigations are proposed. The risk mitigations cover redesigning a transaction energy meter, redesigning the interconnection code, and reviewing the standing operation procedure.

Keywords: power quality, nonlinear load, solar PV, harmonic, risk mitigation.
\end{abstract}

\section{Introduction}

Indonesia has more than 13,000 islands that are located across the equator. At present, the most suitable power plant for these small islands is a diesel power plant. In line with the spirit of reducing its carbon footprint, for the last 7 years, 
the government of Indonesia has instigated several green energy projects [1]. Based on a renewable energy road map, it was announced by the Directorate General of Electricity, Ministry of Energy and Mineral Resources (MEMR) that by 2020 the contribution of renewable energy is expected to comprise 23 percent of total energy consumed.

The electrical power system in Indonesia consists of many grids which are operated independently of each other. Among the many aforementioned grids, the largest one is the Java Bali grid. It covers Java, Madura and Bali island. The profile of this grid is slim and under normal operation, based on operational data per 2014. Power flows from east to west, about 3,350 MW of 22,500 MW peak load. This situation affects power losses, voltage drops, and power system stability risks.

Two years ago, net-metering regulation was proposed by PLN (Perusahaan Listrik Negara) - a state-owned electricity company in Indonesia - for their customers who have solar photo voltaic (PV) systems. The regulation contains procedures on how to interconnect a customer's electrical facility to the PT PLN grid. Then the inflow or ouflow $\mathrm{kWh}$, as a consequence of the interconnection is measured and calculated by an energy meter under a net-metering policy. The more solar PV generators which are integrated into the grid will reduce the load current signifcantly. So, for the distant future, it will support utilities in improving the power flow profile on Java Bali grid.

The International Council on Large Electricity Systems (CIGRE), the Institute of Electrical and Electronics Engineers (IEEE), and the International Energy Agency (IEA) have introduced distributed generation (DG) as distributed resources, electricity generation facilities connected to an electrical power system. One of the emerging energy resources in this decade is solar PV generation. The growing presence of solar PV generation has led to a number of advantages. Besides some advantages mainly when connected close to the load interconnection of solar PV generation into a grid, a number of unusual effects can be occur, such as bidirectional power flows, an increase in fault current level, and PQ disturbance [2]. During abnormal system conditions, such as startup/shut-down, the total harmonic distortion (THD) level may rise higher than $50 \%$ [3]. A lot of PQ research of grid tied solar PVs on a distribution network was undertaken. A PQ study held at solar park showed the highest probability that TDD was the 3rd order followed by the 4th and 5th order [4]. Harmonic emission from solar PV system is the worst during low power generation periods, e.g. at sunrise and sunset [5-7]. Analysis of a residential PV application reveals that critical cases must be considered: the network operating under a light load, the PV system connected at a low short-circuit level point and operating with a leading power factor $[6,8]$. Observation of the PQ effect on a solar PV connected to an unbalanced distribution system showed that the PV inverter supplied balanced currents into a grid and resulted in voltage fluctuations at the point of common coupling (PCC) [9]. Recently, the use of lighting devices have been changing from incandescent lamps to power electronic base lamps. Variation of power affects the harmonic emission a little when the output is large $[8,10,11]$. The nonlinear loads generate less harmonic content if the supply 
voltage is distorted (attenuation effect) [10]. To minimize harmonic emission from a solar PV inverter, a control algorithm can be set up [13, 15]. Base on observation, the PQ disturbance level be affected by inverter performance $[5,8]$.

This paper proposes giving a perspective on implementing integration solar PV without battery storage into a power system. The proposed method is more customized to the local situation and is specifically designed to endorse solar PV application in Indonesia. The main aim of the paper is to recognize risks of interconnection of solar PV generation to a low voltage distribution network related to PQ problem. The identified risk is excessive levels of harmonic current injected by a solar PV system. Moreover, risk mitigations are proposed to minimize harmonic emission from a PV inverter are: to evolve and apply an interconnection code, design and apply an energy meter which is capable of protecting against harmonic emissions, and setting up a standing operation procedure related to supervising solar PV system integration.

This paper is organized as follows: Section 2 describes the results of PQ measurements due to nonlinear loads, section 3 contains typical results of PQ measurements due to power variation of a rooftop solar PV. Risk mitigations to be proposed and future works are presented in section 4. Conclusions are discussed in section 5 .

\section{Nonlinear load measurement}

Since the last decade, PLN have been facing challenging targets related to energy efficiency. At present, their energy losses ares 9.71\% (per 2014). PQ disturbance has become a big issue in PT PLN dealing with the energy losses. Where PQ disturbance is known to be caused by a nonlinear load, it potentially results in energy losses.

Related to the utility and customer interest, the PQ problem can be categorized into: Steady State Voltage Variation, the most basic PQ parameter; Voltage Unbalance, potentially cause additional heating in three phase motors; Voltage Harmonics, Total Harmonic Distortion (THD) is the key harmonic parameter; and Voltage Sags, very short duration changes in voltage magnitude are due to system fault and direct connection of large loads. Based on survey PQ voltage, unbalance, and harmonic THD level disturbance on a strong network is better than on a weak one [12].

The PQ problem in the long term will impact economic effects. A quantification of the economic effects requires the computation of all the consequences related to current and voltage harmonics on all equipment and components. The effects of the harmonic problem can be divided into three main classes: (i) additional losses; (ii) premature aging; (iii) misoperation.

Additional losses result in economic costs, formulated by (1). Where $D_{w}$ is the present worth value of the total loss costs of harmonics, $N_{T}$ is the whole electrical system period.

$$
D w=\sum_{n=1}^{N_{T}}(D w)_{n, p w}=\sum_{n=1}^{N_{T}} \frac{(D w)_{n}}{(1+\alpha)^{n-1}}
$$


Premature aging can be represented by the relative loss of life of the component as is expressed by (2).

$$
\left(\Delta L_{k}\right)_{T_{C}}=\sum_{i=1}^{q}\left[\frac{t_{i, k}}{\Lambda\left(E_{i, k}, \theta_{i, k}\right)}\right]
$$

where $\Lambda\left(E_{i, k}, \theta_{i, k}\right)$ is the useful life, $T_{c}$ is the time period, and $E_{i, k}, \theta_{i, k}$ are the thermal stress.

The amount of the cost due to the misoperation requires the following extensive information: equipment malfunctioning; the process in which the equipment is used; the cost of all the items contributing to lower productivity [2].

In recent years, the trend of using compact fluorescent lamps (CFLs) in Indonesia has drastically increased. Although thorough study has not yet been carried out, extensively using CFLs are convincingly contributing to energy losses significantly due to harmonic distortion.

To know how severe harmonics have been polluting distribution networks typical PQ measurements were performed by PLN in Depok Branch, West Java and Banten Region. The PQ meter used was Fluke 41 and POWERmonic PM30. The measurement was set up on the low voltage side of the distribution substation which supplies commercial and residential areas, where typically these groups use CFLs in large proportions. The results of the measurements are presented in Tables 1-4 and Figures 1 and 2. The shape and spectrum of current among commercial, suburban-residential and rural-residential areas are very similar. Figure 2 depicts a typical harmonic distortion at a rural-residential area. As is shown in Table 1 and Figure 2, harmonics are found in all areas and particularly in neutral wires, current is significantly high.

$$
T H D=\sqrt{\frac{\sum_{2}^{n} I_{n}^{2}}{I_{1}}}
$$

Table 1: Measurement of current at commercial, rural-residential and residential areas.

\begin{tabular}{|l|l|l|l|l|l|l|}
\hline \multirow{2}{*}{$\begin{array}{l}\text { Phase } \\
\#\end{array}$} & \multicolumn{2}{|c|}{ Commercial } & \multicolumn{2}{c|}{$\begin{array}{l}\text { Rural } \\
\text { residential }\end{array}$} & \multicolumn{2}{c|}{$\begin{array}{l}\text { Suburban } \\
\text { residential }\end{array}$} \\
\cline { 2 - 7 } & $\begin{array}{l}\text { I-RMS } \\
(\mathrm{A})\end{array}$ & $\begin{array}{l}\text { THD-I } \\
(\%)\end{array}$ & $\begin{array}{l}\text { I-RMS } \\
(\mathrm{A})\end{array}$ & $\begin{array}{l}\text { THD-I } \\
(\%)\end{array}$ & $\begin{array}{l}\text { I-RMS } \\
(\mathrm{A})\end{array}$ & $\begin{array}{l}\text { THD-I } \\
(\%)\end{array}$ \\
\hline 1 & 269 & 28.7 & 493 & 8.7 & 690 & 8.1 \\
\hline 2 & 257 & 21.8 & 496 & 7 & 776 & 8.4 \\
\hline 3 & 269 & 26.9 & 441 & 7.7 & 824 & 8.2 \\
\hline Neutral & $\mathbf{4 5 . 1}$ & $\mathbf{9 1 . 9}$ & $\mathbf{1 2 0}$ & $\mathbf{8 5 . 3}$ & $\mathbf{2 2 2}$ & $\mathbf{7 9 . 2}$ \\
\hline
\end{tabular}


Table 2: Measurement of phase \#1 current harmonics at SER distribution substation.

\begin{tabular}{|c|c|c|c|c|c|}
\hline Harmonic order & $\boldsymbol{F}(\mathrm{Hz})$ & $\boldsymbol{I}_{\text {mag }}(A)$ & $\boldsymbol{I}_{\boldsymbol{R M S}}(\%)$ & $\Phi\left(^{\circ}\right)$ & $\boldsymbol{P}(\mathrm{kW})$ \\
\hline 1 & 50 & 299 & 99.5 & -24 & 64 \\
\hline 2 & 100 & 0 & 0.1 & 150 & 0 \\
\hline 3 & 150 & 27 & 9 & -176 & 0 \\
\hline 4 & 200 & 0 & 0 & 132 & 0 \\
\hline 5 & 250 & 10 & 3.5 & 27 & 0 \\
\hline 6 & 299.9 & 0 & 0.1 & -164 & 0 \\
\hline 7 & 349.9 & 2 & 0.6 & 136 & 0 \\
\hline 8 & 399.9 & 0 & 0 & -98 & 0 \\
\hline 9 & 449.9 & 2 & 0.6 & -104 & 0 \\
\hline 10 & 499.9 & 0 & 0 & -52 & 0 \\
\hline 11 & 549.9 & 3 & 0.9 & 32 & 0 \\
\hline 12 & 599.9 & 0 & 0 & 131 & 0 \\
\hline 13 & 649.9 & 2 & 0.6 & 146 & 0 \\
\hline
\end{tabular}

Table 3: Measurement of neutral current harmonics at SER distribution substation.

\begin{tabular}{|c|c|c|c|}
\hline Harmonic order & $\boldsymbol{F}(\mathrm{Hz})$ & $\boldsymbol{I}_{\text {mag }}(A)$ & $\boldsymbol{I}_{R M S}(\%)$ \\
\hline 1 & 50 & 38.5 & 44.1 \\
\hline 2 & 100 & 0.4 & 0.4 \\
\hline 3 & 150 & 78 & 89.2 \\
\hline 4 & 200 & 0.2 & 0.3 \\
\hline 5 & 250 & 3 & 3.5 \\
\hline 6 & 299.9 & 0.1 & 0.1 \\
\hline 7 & 349.9 & 2 & 2.3 \\
\hline 8 & 399.9 & 0.1 & 0.1 \\
\hline 9 & 449.9 & 7 & 8 \\
\hline 10 & 499.9 & 0.1 & 0.1 \\
\hline 11 & 549.9 & 0.8 & 1 \\
\hline 12 & 599.9 & 0 & 1.2 \\
\hline 13 & 649.9 & 1.1 & \\
\hline
\end{tabular}

Table 4: $\quad$ Parameters values of SER distribution substation.

\begin{tabular}{|c|c|c|}
\hline Item & Voltage (V) & Current (A) \\
\hline RMS & 230 & 85 \\
\hline Peak & 320 & 134.9 \\
\hline DC Offset & 0 & -0.2 \\
\hline Crest & 1.39 & 1.59 \\
\hline THD Rms & 1.7 & 12.4 \\
\hline THD Fund & 1.7 & 12.5 \\
\hline HRMS & 4 & 10.5 \\
\hline K Factor & & 1.2 \\
\hline
\end{tabular}


(a) Voltage (V)

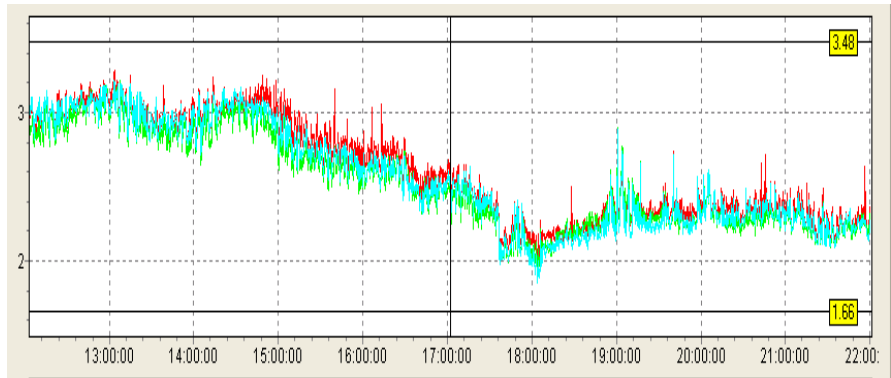

(b) Current (A)

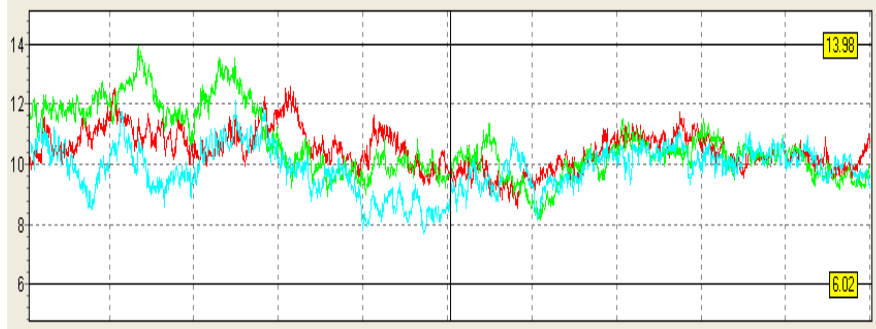

Figure 1: $\quad$ Measured values for harmonic (a) voltages and (b) currents of SER distribution substation.

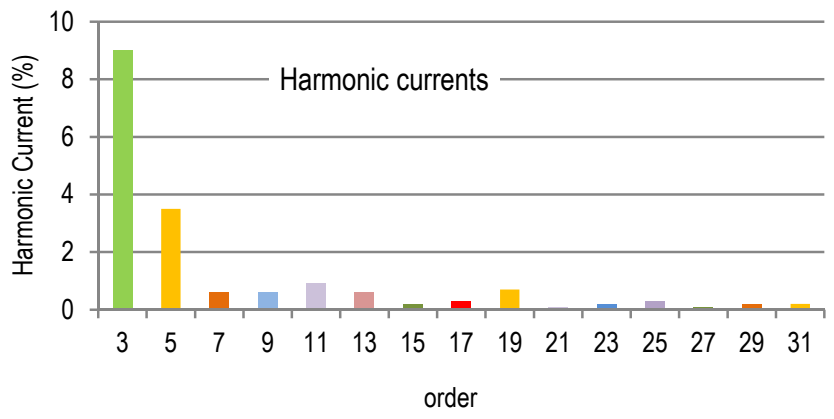

Figure 2: $\quad$ Measured values for phase \#1 harmonic current of SER distribution substation.

The results of this survey indicate that the contribution of current harmonics due to nonlinear loads is significantly high. Table 1 shows that THD of all areas - commercial, rural residential, and suburban residential - exceed the limit of both IEEE 519-1992 and IEEE 1549-2003 standards, whereas as is known current harmonics will impact on energy losses due to neutral current, lessening the true power factor due to a distortion factor, overheating equipment, etc. Therefore the harmonic aspects caused by nonlinear loads must be taken into account for energy loss evaluation. Moreover, in line with the PLN spirit for reducing losses effectively, it is necessary to carry out a thorough investigation, perform continuous measurement and survey the site more and more. 


\section{Variation of power delivered}

Interconnecting rooftop solar PV to a low voltage distribution network is a new experience for PLN. It can be noticed that up to now, only two customers are part of the integration of rooftop PV into the distribution network in this net metering era. The customers aforementioned are residential customer \# xx387 and industrial customer \# xx846. In addition, PLN is anxious to recognize what is the impact of rooftop solar PV integration to a distribution network, at least to the vicinity of point of common coupling (PCC).

To develop techniques to mitigate risks caused by solar PV integration and to support solar PV implementation, PLN continues to intensify PQ investigation particularly related to harmonics emitted by a PV system. From 23 January 2015 to 30 January 2015 and 10 April to 17 April 2015 PLN have performed PQ measurements at the Customer \# xx387 and Customer \# xx846 respectively. A single line diagram of the PQ measurement is shown in Figure 3.

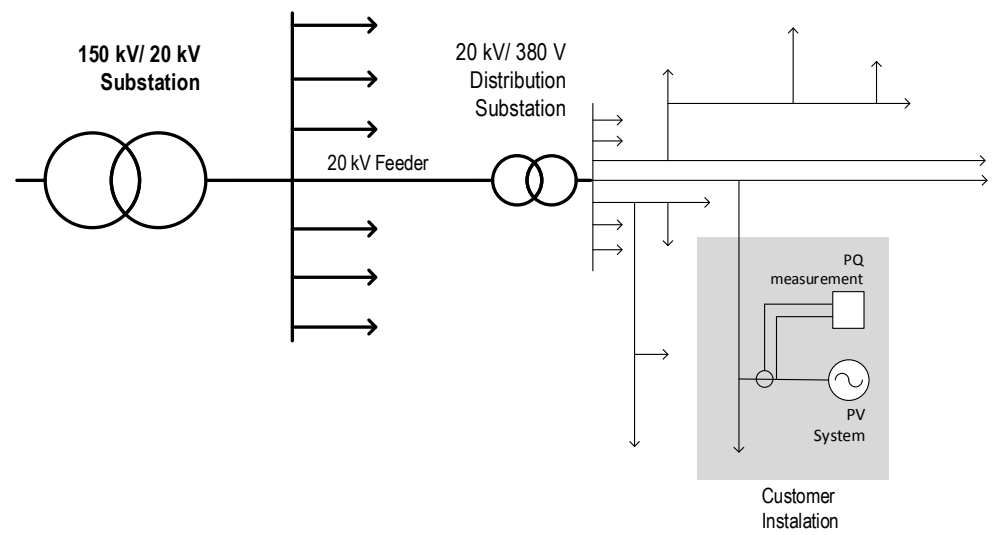

Figure 3: $\quad$ PQ measurement at the PCC close to a customer.

The results of PQ measurements are represented by Figures 4-6 and Table 5 . According to Figure 4, the harmonic current is worse when the fundamental frequency current, I-1st, was obtained during the low periods. These behaviors are similar to the results of $[6,7]$. As well as current harmonics, voltage harmonics show similar behaviors as is shown in Figure 5. A snapshot of delivery power shows unbalanced powers are delivered by an inverter (as depicted by Figure 6).

The PQ measurements indicate a contribution of loads on PQ disturbances are significantly high. Therefore, the PQ disturbances contributed by loads are necessary to be taken account of in evaluating and studying stability. Moreover, the polluted distribution network combining with the harmonics emitted by the PV system is necessary to be studied thoroughly. Regarding these observations, either loads or the solar PV system potentially contribute to PQ disturbances. 


\section{Risk mitigations}

When Tables 1-4 are applied to the site of Customers \# xx387 and \# xx846 then the related rooftop solar PV will inject a large amount of current harmonics of order: $3^{\text {rd }}, 5^{\text {th }}, 7^{\text {th }}, 9^{\text {th }}, 11^{\text {th }}$, and $13^{\text {th }}$ respectively. These results indicate all harmonic levels of current do not meet IEEE 1547-2003.

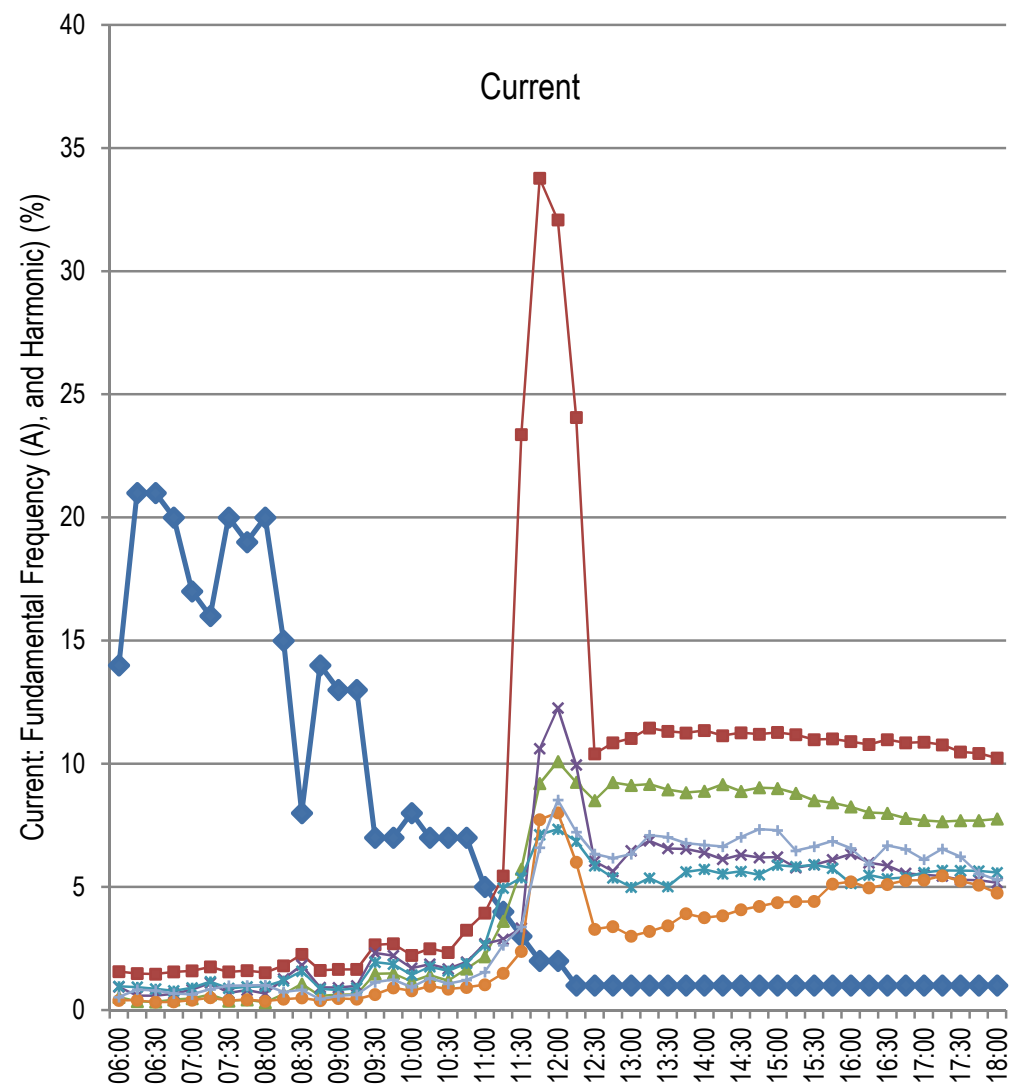

Time (06.00-18.00)

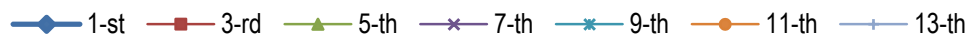

Figure 4: Measured values for current harmonics at the PCC of Customer \# xx387. 


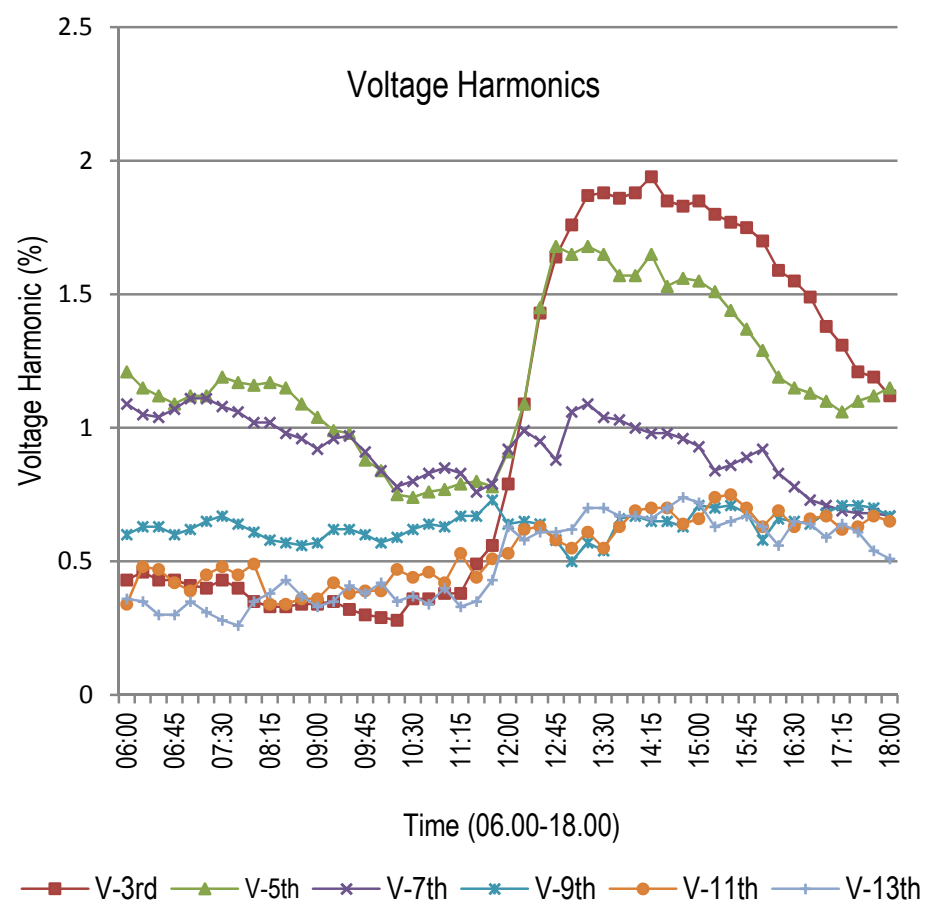

Figure 5: Measured values for voltage harmonics at the PCC of Customer \# xx387.

Table 5: PQ measurement results - voltage and current harmonics due to PV system - and load contributions against the IEEE standard.

\begin{tabular}{|c|c|c|c|c|}
\hline $\begin{array}{c}\text { Harmonic } \\
\text { order }\end{array}$ & $\begin{array}{c}\text { IEEE } \\
\text { 519-1992 } \\
\text { (Voltage) }\end{array}$ & $\begin{array}{c}\text { Voltage } \\
\text { harmonics } \\
\text { emission from } \\
\text { PV (\%) }\end{array}$ & $\begin{array}{c}\text { Current } \\
\text { harmonics } \\
\text { emission from } \\
\text { PV (\%) }\end{array}$ & $\begin{array}{c}\text { Contribution of } \\
\text { nonlinear loads } \\
(\%)\end{array}$ \\
\hline 3rd & $3 *$ & 0.95 & 7.95 & 9 \\
\hline 5 th & $3^{*}$ & 1.18 & 4,80 & 3.5 \\
\hline 7 th & $3^{*}$ & 0.93 & 3.95 & 0.6 \\
\hline 9th & $3^{*}$ & 0.63 & 3.61 & 0.6 \\
\hline 11th & $3^{*}$ & 0.52 & 2.65 & 0.9 \\
\hline 13th & $3^{*}$ & 0.48 & 3.79 & 0.6 \\
\hline 15th & $3 *$ & NA & NA & 0.2 \\
\hline THD/TDD & 5 & NA & NA & 9.8 \\
\hline
\end{tabular}




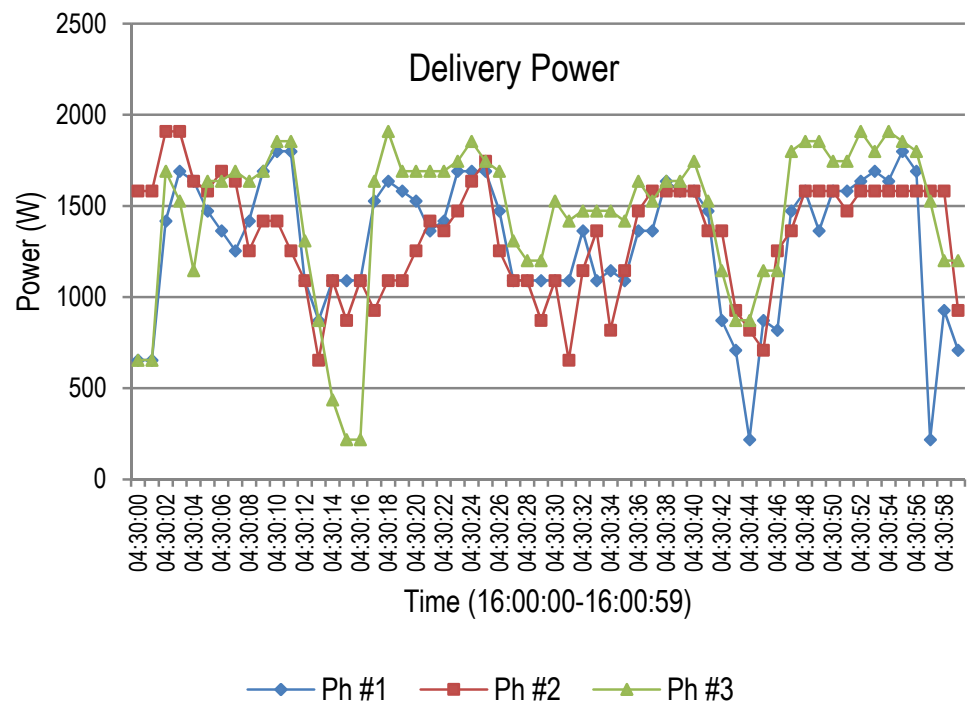

Figure 6: Measured values for real power at the PCC of Customer \# xx846.

Some problems are found on implementing a grid connected rooftop solar PV. Problems such as: how to control emission harmonics from a rooftop solar PV, how to ensure the distribution network will be safe particularly for a lineman, and how to evolve the distribution code and meter standard to ensure PQ meet the IEEE 1547-2003 standard. To solve these risks, risk mitigations are proposed, such as redesigning the transaction energy meter, review connection code, and plan future work.

\subsection{Energy meter standard}

To control PQ due to rooftop solar PV integration, the utility has been setting up a related energy meter standard. The standard covers meter abilities on measuring power flow bedirectionally, harmonics, normal/ abnormal voltage and frequency, etc. The energy meter takes a role to protect the grid against PQ disturbance and anti islanding due to the prevailing distribution code.

Related to the bidirectional feature, the energy meter design will be equipped with three registers: sending, receiving and summation of energy. Regarding the harmonic feature, the energy meter design has the capability to measure and record harmonics as stated by IEEE 1547-2003. In relation to the interconnection feature, the energy meter is designed to detect abnormal voltage and frequency as stated by IEEE 1547-2003 and sends command to the protection unit when abnormal conditions occur in the interconnection. 


\subsection{Connection code}

To ensure stability and security of the distribution network due to interconnection of a rooftop solar PV, the utility has set up a connection code. The code covers anti islanding aspects, parallel aspects, and standing operation aspects coresponding to lineman safety and distribution network security.

\subsection{Modelling rooftop solar PV integration}

An observation reveals current THD of a nonlinear load is influenced by the supply voltage waveform. A distorted voltage impacts on higher current THD than a sinusoidal one [10]. The other observation states that current THD of PV is significantly dependent on the voltage harmonic content of a power system [6]. When the distribution network has highly nonlinear loads combining with the PV system can induce undesirable harmonic components [5]. Regarding these observations, this paper proposes a model of a PV system interconnection as shown by (4) and (5), (4) when the PV system is installed close to loads and (5) when the PV system is directly interconnected to a bus of substation.

$$
\begin{gathered}
i_{p v}=f(\text { irradiance, temperature }) \\
i_{p v}=f\left(\text { irradiance,temperature }, v_{\text {grid }}\right)
\end{gathered}
$$

\section{Conclusion}

PQ analyses of the rooftop PV integration into distribution network have been discussed in this paper. The result of PQ measurements indicate that the contribution of loads on PQ disturbances are significantly high. Therefore, it is necessary to take account of PQ disturbances contributed by loads when evaluating losses and studying power system stability. Moreover, it is necessary to thoroughly study the polluted distribution network combining with the harmonics emitted by PV system.

The risk mitigations have been proposed briefly. To endorse the application of a solar PV system in Indonesia typical strategies are needed. Based on PLN evaluation, the appropriate strategies are as mentioned in 4.1, 4.2 and 4.3; where preferred approaches are mitigating integration risk rather than performing hardware, such as inverter, MPPT, etc. Furthermore, these risk mitigations will be developed in the next work.

\section{References}

[1] Hadi Suhana, IG Agung Sutedja, Adi Priyanto \& Pekik Argo Dahono, An Operational Experience of Wind-Diesel Hybrid Power System in Indonesia, EEEIC, Rome, Italy, 2011.

[2] Pierluigi Caramia, Guido Carpinelli \& Paola Verde, Power Quality Indices in Liberalized Markets, Wiltshire, UK, John Wiley and Sons, Ltd, 2009, pp. 215-217. 
[3] Christine D Crites, Rajiv K Varma, Vinay Sharma \& Bill Milroy, Characterization of Harmonics in a Utility Feeder with PV Distributed Generation, IEEE, 2012.

[4] Alejandro R. Oliva \& Juan Carlos Balda, A PV Dispersed Generator: A Power Quality Analysis within the IEEE 519, IEEE Transactions on Power Delivery, Vol. 18, No. 2, April 2003.

[5] Annapoorna Chidurala, Tapan Kumar Sha, N Mithulananthan \& Ramesh C Bansal, Harmonic Emission in Grid Connected PV System: A Case Study on a Large Scale Rooftop PV Site, School of Information Technology and Electrical Engineering, The University of Queensland, Australia with Dept. of Electrical, Electronic \& Computer Engineering, University of Pretoria, Pretoria, South Africa.

[6] Pedro A.B. Block, Henry L. L. Salamanca, Mateus D. Teixeira, Diogo B. Dahlke, Otavio M. Shiono, Antonio R. Donadon \& Joao C. Camargo, Power Quality analyses of a Large Scale Photovoltaic System, The fifth International Renewable Energy Congress IREC, Hammamet, Tunisia, March 25-27, 2014.

[7] Gianfranco Chicco, Jurgen Schlabbach \& Filippo Spertino, Characterisation and Assessment of the Harmonic Emission of GridConnected PV System.

[8] Ricardo Torquato, Fernanda C.L. Trindade \& Walmir Freitas, Analysis of the Harmonic Distortion Impact of Photovoltaic Generation in Brazilian Residential Network, 2014.

[9] Annapoorna Chidurala, Tapan Kumar Saha \& N. Mithulananthan, Power Quality Enhancement in Unbalanced Distribution Network using SolarDSTATCOM, Australasian Universities Power Engineering Conference, AUPEC 2013, Hobart, TAS, Australia, 29 September-3 October 2013.

[10] Ana Maria Blanco, Robert Stiegler \& Jan Meyer, Power Quality Disturbances caused by Modern Lighting Equipment (CFL and LED), Technische Universität Dresden, Dresden, Germany.

[11] Yang Wang, Hesam Yazdanpanahi \& Wilsun Xu, Harmonic Impact of LED Lamps and PV Panels, 26th IEEE Canadian Conference of Electrical and Computer Engineering (CCECE), 2013.

[12] Sean Elphick, Vic Smith, Vic Gosbell \& Robert Barr, Characteristics of Power Quality Disturbance Levels in Australia, IEEE, 2012.

[13] Jurgen Schlabbach, Andreas Grob \& Gianfranco Chicco, Influence of Harmonic system Voltages on the Harmonic Current Emission of Photovoltaic Inverters, Powering 2007, April 12-14, 2007.

[14] Pedro Gonzalez, Enrique Romero, Victor M Minambres \& Miguel A Guerrero \& Eva Gonzalez, Grid-Connected PV Plants. Power Quality and Technical Requirements, IEEE, 2014.

[15] Nilesh Shah \& R Chudamani, Grid Interative PV System with Harmonic and Reactive Power Compensation Features Using a Novel Fuzzy Logic Based MPPT, IEEE, 2012. 